\title{
Analysis of Mechanical Properties of Sandstone under Freeze- Thaw Cycles Based on Digital Image Correlation (DIC)
}

\author{
Daguo Quan, ${ }^{1,2}$ Shuailong Lian, ${ }^{1,2}$ Jing Bi $\mathbb{D}^{1,2}$ and Chaolin Wang ${ }^{1,2}$ \\ ${ }^{1}$ College of Civil Engineering, Guizhou University, Guiyang 550025, China \\ ${ }^{2}$ Guizhou Provincial Key Laboratory of Rock and Soil Mechanics and Engineering Safety, Guiyang 550025, China \\ Correspondence should be addressed to Jing Bi; demonjjun@126.com
}

Received 23 May 2021; Accepted 5 July 2021; Published 9 August 2021

Academic Editor: Yu Wang

Copyright (C) 2021 Daguo Quan et al. This is an open access article distributed under the Creative Commons Attribution License, which permits unrestricted use, distribution, and reproduction in any medium, provided the original work is properly cited.

\begin{abstract}
This paper studies the change of physical and mechanical properties of sandstone after freeze-thaw (F-T) cycle treatment. Firstly, the effects of the freeze-thaw treatment on the P-wave velocity of sandstone specimens are analyzed. It is found that the P-wave velocity decreases with the increase of the number of freeze-thaw cycles. Secondly, the effect of freeze-thaw treatment on the mechanical properties of sandstone is analyzed. The results show that the tensile strength and compressive strength of sandstone samples decrease with the increase of the number of freeze-thaw cycles. Finally, the digital image correlation (DIC) technique was used to collect the full-field deformation data of the samples, and the influence of freeze-thaw cycles on the deformation characteristics and fracture process of sandstone was analyzed. Based on the standard deviation of the principal strain in the field deformation data, the damage variables were proposed to characterize the damage process of sandstone samples in the Brazilian splitting test and the uniaxial compression test. The results show that the proposed damage variables can reflect the damage evolution process of the sample effectively. According to the variation of damage variables, the damage evolution process of sandstone specimens during the Brazilian splitting test and the uniaxial compression test can be divided into three stages: slow or negative growth stage, stable growth stage, and rapid growth stage. The research results are of great significance for predicting the failure mode and damage evolution of rock mass engineering by using digital image correlation technology.
\end{abstract}

\section{Introduction}

In China, cold regions account for $75.8 \%$ of the total land area [1]. In cold areas, ambient temperatures above or below the freezing point can trigger freeze-thaw cycles. The damage and deterioration of rock mass caused by freezing and thawing have caused a series of geological engineering problems, such as frost heave cracking of tunnel linings [2], deformation of high-speed railway subgrades [3], weathering and denudation of rock slope [4], and instability of high and steep dangerous rock mass [5]. Therefore, it is of great significance for engineering construction in cold areas to study the damaged mechanical properties of rock specimens after freezethaw treatment under load conditions.
In recent years, the research on freeze-thaw rocks has made rapid progress, and many outstanding achievements have been made [6,7]. Fukuda et al. [8] studied the effects of temperature, particularly minimum and cooling temperatures, on rocks. Wen et al. [9] analyzed the physical and mechanical properties of rocks at low temperatures $\left(-10^{\circ} \mathrm{C}\right.$, $-20^{\circ} \mathrm{C},-30^{\circ} \mathrm{C}$, and $-40^{\circ} \mathrm{C}$ ), and the results showed that low temperature could greatly affect the frost resistance of rocks. Prick [10] determined the occurrence of freeze-thaw cycle damage based on the saturation threshold. Tan et al. [11] studied the damage mechanism of granite after freeze-thaw treatment and concluded that the mechanical parameters of granite decreased exponentially with the number of freezethaw cycles. Khanlari and Abdilor [12] studied the influence 
of the pore size on the mechanical properties of sandstone after freeze-thaw treatment and concluded that the particle size and particle contact did not achieve the expected effect on the damage of sandstone samples during the freeze-thaw cycle.

At the same time, with the emergence of some advanced equipment, researchers have applied it in rock mechanics tests and tried to study the damage evolution process of the rock mass from multiscale. The acoustic emission (AE) technique is a common method for the nondestructive testing of rock. The spatiotemporal evolution characteristics of acoustic emission events can be used to reflect the damage state of rock during loading $[13,14]$. In order to characterize the failure process of rock more intuitively, some parameters such as acoustic emission energy, event counts, and ringing counts were applied to the damage theory, and a new damage variable was proposed to reflect the evolution of rock damage [15]. The computer tomography (CT) and the scanning electron microscope (SEM) are also extensively used in the study of failure modes and microscopic crack propagation of rock $[16,17]$.

DIC technology, as a new optical detection method, can be used to study the surface strain field information of materials without out-of-plane motion. It possesses many advantages, such as simple experimental steps, high accuracy, and high computational efficiency [18-22]. At present, many researchers begin to apply DIC in mechanical tests to obtain the full-field strain information on the surface of quasibrittle materials. For example, Leplay et al. [23] analyzed the crack propagation law and failure mode on the surface of ceramic materials by DIC; Zhang et al. [24] studied the fracture mode of sandstone under compression through digital image correlation technology. Ma et al. [25] used DIC to analyze the damage evolution process of granodiorite during the splitting test. Therefore, the DIC technology can be used to effectively characterize the damage evolution process of rock materials.

Compared with CT, SEM, and AE, DIC has many advantages such as full-field observation, high accuracy, low cost, and large test range [26]. Therefore, based on the advantages of the above DIC technology, this paper studies the deformation characteristics and failure process of sandstone after freeze-thaw cycles. The damage evolution process of sandstone under freeze-thaw cycles is quantitatively analyzed using the standard deviation of the principal strain as the damage variable. The research results are of great significance for predicting the failure mode and damage evolution of rock mass engineering by using digital image correlation technology.

\section{Experimental Setup and Specimen Preparation}

2.1. 2D-DIC Setup. DIC technology has been widely used in recent years because of its unique advantages of noncontact measurement, full-field strain, displacement data extraction, and high precision. This paper adopts theVIC-2D field strain test system. It is mainly composed of an industrial camera, lens, light source, speckle tool, computer, and image analysis software.
2.1.1. Principle of 2D-DIC. As an optical measurement technique, DIC measures the two-dimensional or threedimensional coordinates of the whole field constantly changing on the sample surface during the entire mechanical test process. The measured coordinate fields can be used to derive further the areas of displacement, strain, strain rate, velocity, and curvature of interest (Quantities-of-Interest, QOI). As shown in Figure 1, the core idea of DIC is to estimate the coordinates and displacements of full-field speckle based on a series of digital speckle images of sample surfaces by solving optimization problems. The basic assumption in DIC is that the speckle pattern on the sample surface should deform along with the sample, whether natural or artificial. Therefore, the speckle image taken on the sample surface can be used for correlation calculation to obtain its full-field coordinates, which can be used to characterize the shape, movement, and deformation of the sample surface. A single-camera system to measure the $2 \mathrm{D}$ coordinates of a flat sample surface is called 2D-DIC.

2.1.2. 2D-DIC Image Acquisition Method. As can be seen in Figure 1, the VIC-2D-DIC image acquisition system is mainly composed of a fixed-focus lens with a focal length of $50 \mathrm{~mm}$, a CCD industrial camera, two high-brightness light sources, a computer, and image analysis software. The image size of the CCD industrial camera is $4096 \times 3000$. In the test, the camera should be aligned with the center of the sample, and the image size of the sample should be adjusted to reach the same size as the camera vision. DIC collects images at a rate of 10000 per second during the experiment.

\subsection{Sample Preparation and Test Procedure}

2.2.1. Sample Preparation. The rock sample used in this paper is fine red sandstone, and the fine red sandstone sample is processed and polished according to the Standard of the International Society for Rock Mechanics (ISRM). According to the requirements of the paper, two sizes of sandstone samples are processed: one is a standard cylinder sample with a height of about $100 \mathrm{~mm}$ and a diameter of about $50 \mathrm{~mm}$ and the other is a standard disc specimen with a height of about $25 \mathrm{~mm}$ and a diameter of about $50 \mathrm{~mm}$. The processed sandstone samples are shown in Figure 2.

2.2.2. Test Procedure. Rock lithology, temperature, water saturation rate, and the number of cycles are the critical influencing factors of the freeze-thaw cycle test. Therefore, according to the requirements, the test plan is as follows:

(1) To select samples with similar lithology for the test, the wave velocity of the two processed samples was measured, and the sandstone samples with similar wave velocities were selected

(2) The sample is dried by an electric thermostatic drying oven, making the sample more easily absorb water and saturate. The dried sample is immersed in the vacuum water-filling device for 24 hours to make it fully saturated 

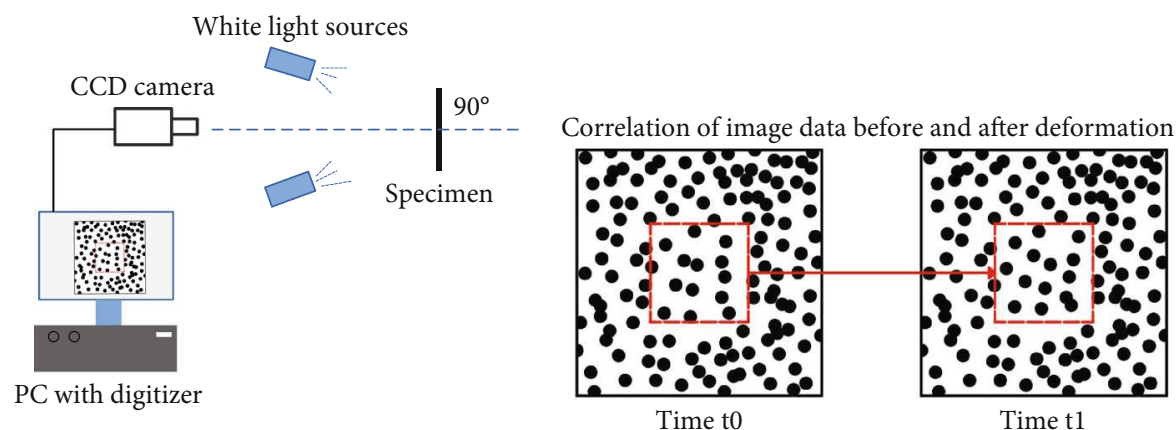

Figure 1: 2D-DIC schematic diagram.

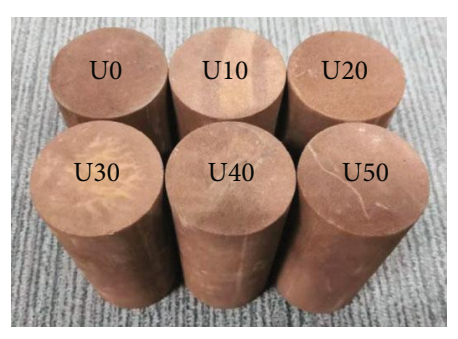

(a) Uniaxial compression samples

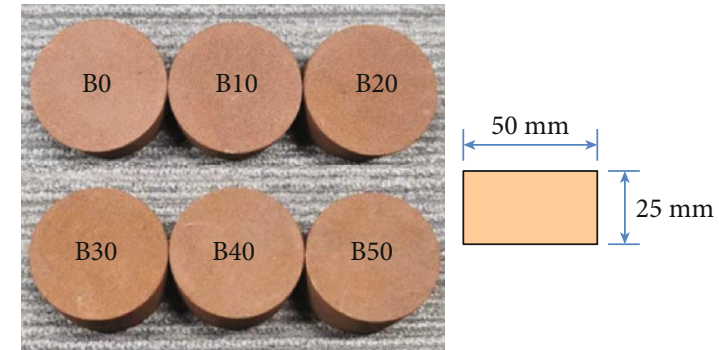

(b) Brazilian split samples

FIGURE 2: The processed sandstone samples.

(3) Then, the samples are placed into the freeze-thaw cycle test equipment for the freeze-thaw cycle treatment. The freezing temperature was set as $-20^{\circ} \mathrm{C} \pm$ $2^{\circ} \mathrm{C}$, and the freezing time was 3 hours. The thawing temperature was set as $20^{\circ} \mathrm{C} \pm 2^{\circ} \mathrm{C}$, the thawing time was 3 hours, and the one freeze-thaw cycle was 6 hours. The relationship between temperature and time in freeze-thaw cycles can be seen in Figure 3. Then, $0,10,20,30,40$, and 50 freeze-thaw cycle tests were completed. After the freeze-thaw cycle test, the wave velocity of the sample was measured to observe the degree of damage. The grouping of freeze-thaw cycle test samples can be seen in Table 1

(4) The test equipment used in this study is the DSZ-1000 stress-strain controlled rock mechanics testing system, and the maximum axial force that could be applied by the test system was $1000 \mathrm{kN}$. For the DIC principle, an ideal speckle with a diameter of $0.33 \mathrm{~mm}$ should be made on the sample surface by the speckle tool before the start of the mechanical test. After the speckle production, dry the sample surface with the normal temperature air of a hairdryer and put the sample on the DSZ-1000 test machine. Adjust the position of the sample and the angle of the camera lens so that the center of the sample is aligned with the center of the camera field of view. The loading method of this mechanical test is force control; the loading rate was set as $0.05 \mathrm{MPa} / \mathrm{s}$. The primary test devices and their processes are shown in Figure 4

\section{Results and Analysis}

3.1. Variation of Longitudinal Wave Velocity of Sandstone after Freeze-Thaw Treatment. In this test, ultrasonic equipment was used to test the internal condition of sandstone before and after freeze-thaw treatment. Ultrasonic monitoring is a nondestructive testing method that uses ultrasonic waves to propagate in a certain velocity and direction in the material with internal defects and then obtain the obvious change of its acoustic properties. Because of the fast propagation speed of the $\mathrm{P}$-wave in materials, the $\mathrm{P}$-wave is generally used to detect material properties.

As can be seen in Figure 5, with the increase of the number of freeze-thaw cycles, the wave velocity of saturated rock samples showed a decreasing trend. Quadratic polynomial functions can represent both, and the fitting formula is as follows:

$$
\bar{V}=-0.011 N^{2}-3.412 N+1728 .
$$

$\bar{V}$ is the average value of the P-wave velocity, $N$ is the number of cycles, and the relative coefficient between the two is $R^{2}=0.987$. Along with the whole freeze-thaw cycle test, the longitudinal wave velocity of the sandstone sample decreases greatly, with a maximum decrease of $10.84 \%$. The main reason for the decrease of the $\mathrm{P}$-wave velocity is that the water forms change under the action of temperature, which exerts a certain large frost heave force on the interior of the sandstone, resulting in the expansion and increase of microcracks and micropores in the sandstone. At the same time, in the melting process of the ice in the sandstone, the 


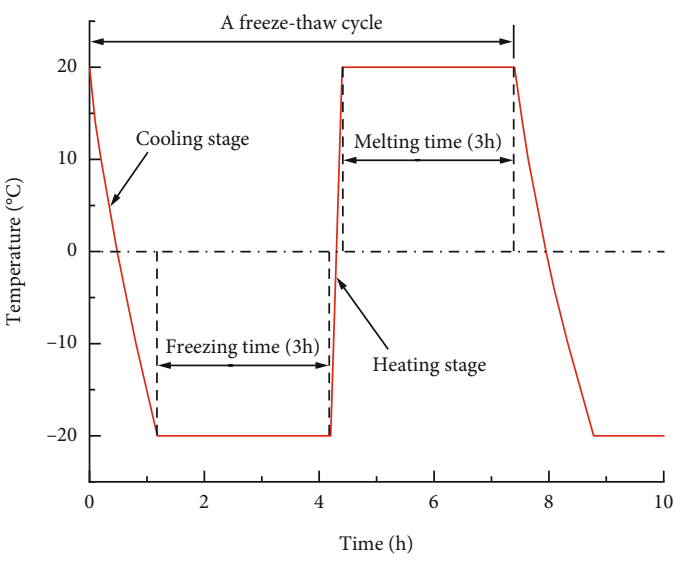

FIgURE 3: The relationship between temperature and time in freeze-thaw cycle test.

external water keeps entering new microcracks and micropores, resulting in the increasing proportion of water in the sandstone. However, the propagation velocity of the P-wave in water is lower than that in rock, so the propagation velocity of the P-wave in the sandstone is significantly reduced after freeze-thaw treatment.

\subsection{Study on the Law of Tensile Strength of Sandstone under Freeze-Thaw Cycles}

3.2.1. Load-Displacement Curves of Sandstone Samples. The load-displacement curves of B0, B10, B20, B30, B40, and $\mathrm{B} 50$ are shown in Figure 6; taking B50 as an example, four key points, O, A, B, and $\mathrm{C}$, were selected from the loaddisplacement curve of theB50 specimen and analyzed in the following section.

As can be seen in Figure 6, the load-displacement curves of sandstone samples after freeze-thaw treatment were basically the same under the splitting test. By comparing these six groups of load-displacement curves, it is found that when the number of freeze-thaw cycles increases continuously, the tensile strength and displacement of sandstone samples both show a decreasing trend. When the number of freeze-thaw is small, the peak tensile strength and peak displacement decrease slowly, indicating that the effect of freeze-thaw on tensile strength is small in the early stage. With the increase of freeze-thaw times, the internal damage of sandstone accumulates continuously. The peak tensile load and peak displacement decrease rapidly, and the decrease is noticeable compared with that in the early freeze-thaw period. This phenomenon indicates that after multiple freeze-thaw cycles, the sandstone suffered severe damage inside the rock, which led to the more easy failure of the rock under tensile load during the Brazilian splitting test, showing a decreasing trend of both tensile load and displacement.

3.2.2. Failure Characteristics of Sandstone Samples under Different Freeze-Thaw Cycles. In this section, the characteristic $X$-direction main strain was analyzed by selecting the strain cloud diagram of ROI (region of interest) on the samples B0, B10, B20, B30, B40, and B50. Table 2 shows the evolution process of the $X$-direction main strain cloud diagram of the sample before reaching the maximum load in the splitting test.

From the results obtained in Table 2, for the sandstone specimens B0, B10, B20, B30, B40, and B50 under the condition of freeze-thaw cycles, when the load applied reaches $0.2 \sigma_{c}$, the strain field appears in the entire Brazilian disc due to load action. In the Brazilian splitting test, stress concentration was generated at the end of the Brazilian disc due to loading along the diameter. The maximum strain value in the strain field appeared at both ends of the Brazilian disc. When the load reaches $0.9 \sigma_{c}$, a large strain concentration region is formed at the end of the Brazilian disc, and the deformation region of the strain band begins to gather, making the strain band more obvious. With the increase of load, cracks in the Brazilian disc develop rapidly. The strain field is constantly spreading from one end of the sample to the other, which makes the strain concentration area larger. When the load reaches the peak $\sigma_{c}$, microcracks appear on the surface of one end of the disc, indicating that the Brazilian disc starts to crack from one end. Finally, under the continuous action of the load, the microcrack expands rapidly from one end of the disc to the center, resulting in a larger crack.

As mentioned above, during the splitting test of the freeze-thaw-treated sandstone sample, the pores and cracks in the disk will increase, and with the increase of the number of freeze-thaw cycles, the strain difference between the end and the middle of the sandstone gradually decreases. The crack initiation location of the Brazilian disc may change from the end to the middle.

\subsection{Study on the Law of Compressive Strength of Sandstone under Freeze-Thaw Cycles}

3.3.1. Stress-Strain Curve of Sandstone Samples. The stressstrain curves of U0, U10, U20, U30, U40, and U50 are shown in Figure 7; taking U50 as an example, five key points, O, A, $\mathrm{B}, \mathrm{C}$, and $\mathrm{D}$, were selected from the stress-strain curve of the U50 sample and analyzed in the following section.

As can be seen in Figure 7, the stress-strain curves of sandstone samples after freeze-thaw treatment were basically the same under the uniaxial compression test, which all go through the compaction stage, elastic stage, and yield stage, and then, the sample is destroyed abruptly. The failure characteristic is a typical brittle failure. By comparing these six groups of stress-strain curves, it is found that with the increase of the number of freeze-thaw cycles, the peak strength presents a decreasing trend, while the peak strain presents an increasing trend. When the number of freezethaw cycles is less than 30 times, the stress-strain curve of sandstone is similar to the stress-strain curve without freeze-thaw, which is relatively smooth, and the peak strain only increases by $6.62 \%$, until the failure occurs suddenly at the ultimate load. When the number of freeze-thaw cycles reaches 50 times, the peak strength decreases, and the peak strain increases significantly. The stress-strain curve is smooth and stable in the compaction zone and the elastic zone. However, after entering the plastic zone, the stressstrain curve fluctuates wildly because the freeze-thaw cycle 
TABLE 1: The grouping of freeze-thaw cycle test samples.

\begin{tabular}{|c|c|c|c|c|c|c|c|}
\hline \multicolumn{8}{|c|}{ Grouping basis and number } \\
\hline \multirow{2}{*}{ Loading method } & The uniaxial compression & U0 & U10 & $\mathrm{U} 20$ & U30 & $\mathrm{U} 40$ & $\overline{\mathrm{U} 50}$ \\
\hline & The Brazilian splitting & B0 & $\mathrm{B} 10$ & $\mathrm{~B} 20$ & B30 & B 40 & B50 \\
\hline
\end{tabular}

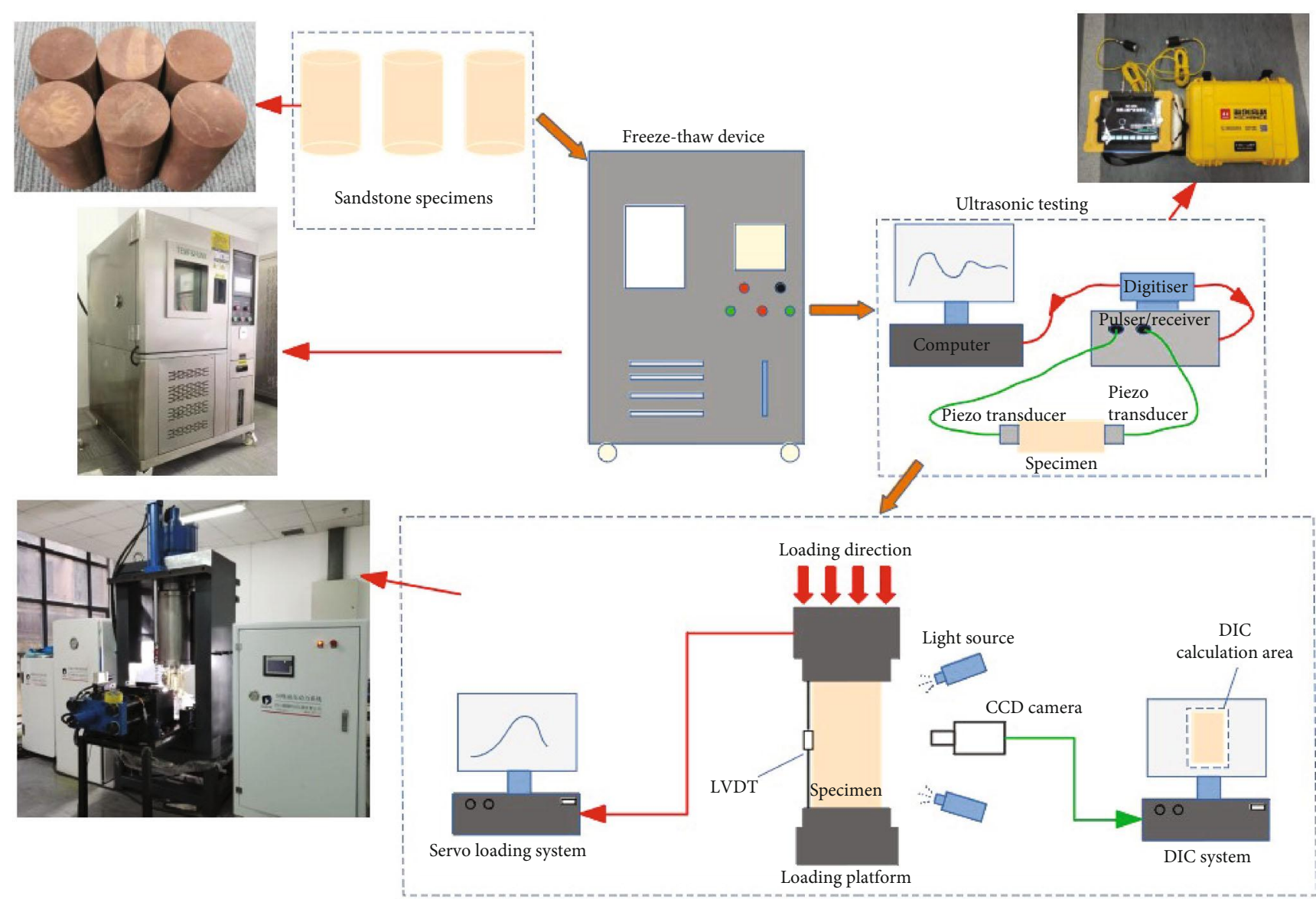

Figure 4: The main equipment and test flow chart.

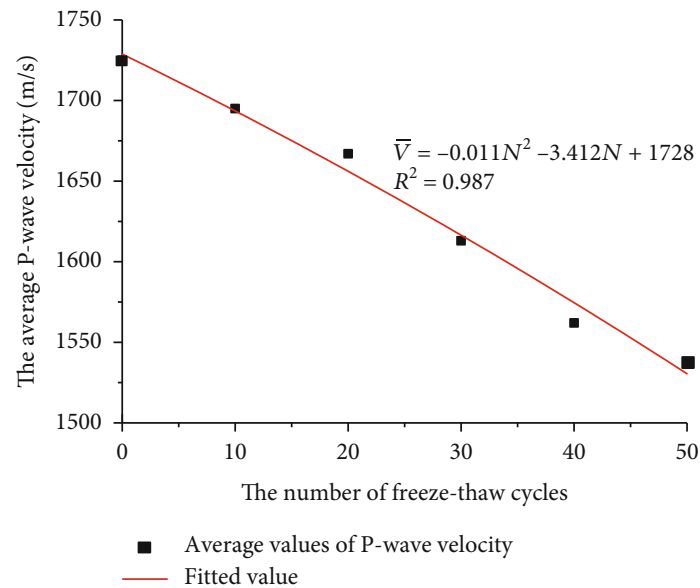

FIgURE 5: Variation of mean P-wave velocity of uniaxial compression samples under different freeze-thaw cycles. causes irreversible damage to the interior of the sandstone. With the increase of the number of freeze-thaw cycles, the frost heave force caused by water freezing squeezes the micropores inside the sandstone, causing damage to the sample. With the passage of time, the accumulation of damage leads to the continuous expansion of microcracks, which leads to the decrease of peak strength and the increase of peak strain.

3.3.2. Failure Characteristics of Sandstone Samples under Different Freeze-Thaw Cycles. In this section, the deformation and failure modes were analyzed by selecting the strain cloud diagram ( $X$-direction) of ROI (region of interest) on the samples U0, U10, U20, U30, U40, and U50. Table 3 shows the evolution process of the $X$-direction strain cloud diagram of the sample before reaching the maximum load in the uniaxial compression test.

From the results obtained in Table 3, for the sandstone sample U0 without freeze-thaw cycle treatment, before the 


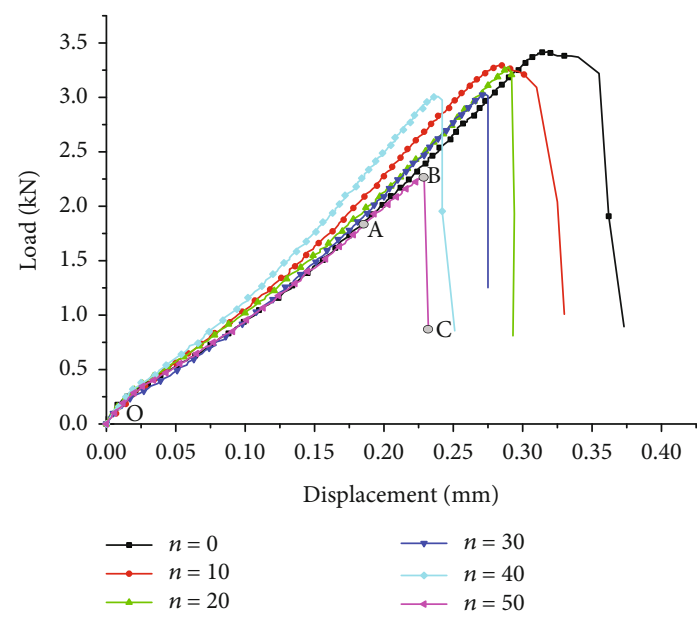

Figure 6: Load-displacement curves of Brazilian splitting test.

peak stress reaches $0.4 \sigma_{\mathrm{c}}$, some smaller strain concentration regions are distributed in the upper right side of the sample U0. When the peak stress is between $0.5 \sigma_{c}$ and $0.6 \sigma_{c}$, the strain concentration area in the upper right part of the sample begins to diverge to the periphery and gradually develops into a relatively clear strain band. When the peak stress is between $0.7 \sigma_{c}$ and $0.9 \sigma_{c}$, the strain concentration region at both ends of the sample begins to form initially and extends along the vertical direction, slowly connecting with the strain concentration region in the middle of the right side of the sample. When the peak stress $\sigma_{c}$ is reached, the strain concentration region at the tip of the specimen develops rapidly, and its propagation path is consistent with the actual failure crack of the specimen.

For the sandstone sample U10 after ten freeze-thaw cycles, before the peak stress up to $0.6 \sigma_{c}$, some small strain concentration areas are scattered at the end of the U10 sample. When the stress increases from $0.7 \sigma_{\mathrm{c}}$ to $0.9 \sigma_{\mathrm{c}}$, the strain concentration zone develops rapidly at the lower end of the specimen. Unlike the failure process of specimen U0, the width of the strain concentration zone increases gradually. When the peak stress $\sigma_{c}$ is reached, a large strain concentration area is formed at the lower end of the sample. For samples U20 and U40, the process from loading to failure is similar to that of U10, and strain concentration areas are formed at the lower end, and when the peak stress $\sigma_{\mathrm{c}}$ is reached, the lower end of the sample will be damaged first.

For the sandstone sample U30 after 30 freeze-thaw cycles, before the peak stress up to $0.4 \sigma_{c}$, there is a small strain concentration area scattered in the middle of the surface of specimen U30. When the stress reaches $0.5 \sigma_{c}$, the strain concentration area appears at the upper end of the sample. When the stress increases from $0.6 \sigma_{c}$ to $0.9 \sigma_{c}$, the strain concentration area develops rapidly in the middle and the end of the sample. When the peak stress $\sigma_{\mathrm{c}}$ is reached, an oblique strain concentration area and a strain concentration area parallel to the sample are formed. For the sandstone sample U50, the process from loading to failure is similar to that of U30. A small strain concentration area is formed at one end of the sample of U30 at first. With the increase of stress, the strain concentration area gradually widens and moves towards the other end of the sample. Finally, an oblique strain concentration area is formed in the sample.

In summary, in the process of uniaxial compression of sandstone samples after freeze-thaw treatment, the more times of freeze-thaw cycles, the greater the strain of sandstone samples will be. The reason is that the freezing and thawing cause irreversible damage in the interior of the sandstone. With the accumulation of freeze-thaw damage, the influence of internal frost heaving force on the microcracks gradually increases, leading to the expansion and connection of microcracks, and the bearing capacity of the specimen decreases, and the number of deformation increases.

\section{Damage Assessment of Sandstone Samples under Freeze-Thaw Cycles Based on 2D-DIC}

4.1. Establishment of Damage Variables. In rock mechanics, the degradation of rock strength is caused by internal damage, and the accumulation of the damage will inevitably lead to the change of the strain field on the surface of the specimen. Therefore, the internal damage of rock can be represented by an index of strain field concentration. Based on the above, damage variables [27] can be expressed by

$$
D=\frac{\mathrm{S}}{\mathrm{S}_{\max }} .
$$

In Equation (2), $S$ is the standard deviation of the strain field, as shown in Equation (3). $S_{\max }$ is the maximum value of $S$ (generally at the failure point) during the whole loading process.

$$
S=\sqrt{\frac{1}{n-1} \sum_{k-1}^{n}\left(X_{k}-\bar{X}\right)^{2}} .
$$

In Equation (3), $X_{k}$ is the strain value at each point within the strain field. $\bar{X}$ is the average of $X_{k}$, and $n$ is the total number of data points in the strain field.

\subsection{Damage Analysis of Samples under the Brazilian Splitting} Test. The damage evolution process of B0, B10, B20, B30, B40, and $\mathrm{B} 50$ specimens has been analyzed. After the image analysis software was used to obtain the principal strain of the strain field in the $X$-direction of the sample, and the maximum standard deviation of the principal strain in the $X$-direction was calculated, the maximum standard deviation was substituted into Equation (2) to calculate the damage variable.

As shown in Figure 8, the damage evolution of sandstone in the splitting process under different freeze-thaw cycles can be divided into three stages: in the first stage (period of slow or negative growth), the damage variable was small. This is because the sample in this stage is subjected to a small load, which is not enough to destroy the cohesion inside the sandstone and is not enough to generate new microcracks and micropores. Even due to the action of the load, the internal microcracks in B0 and B10 are compressed and closed, the 


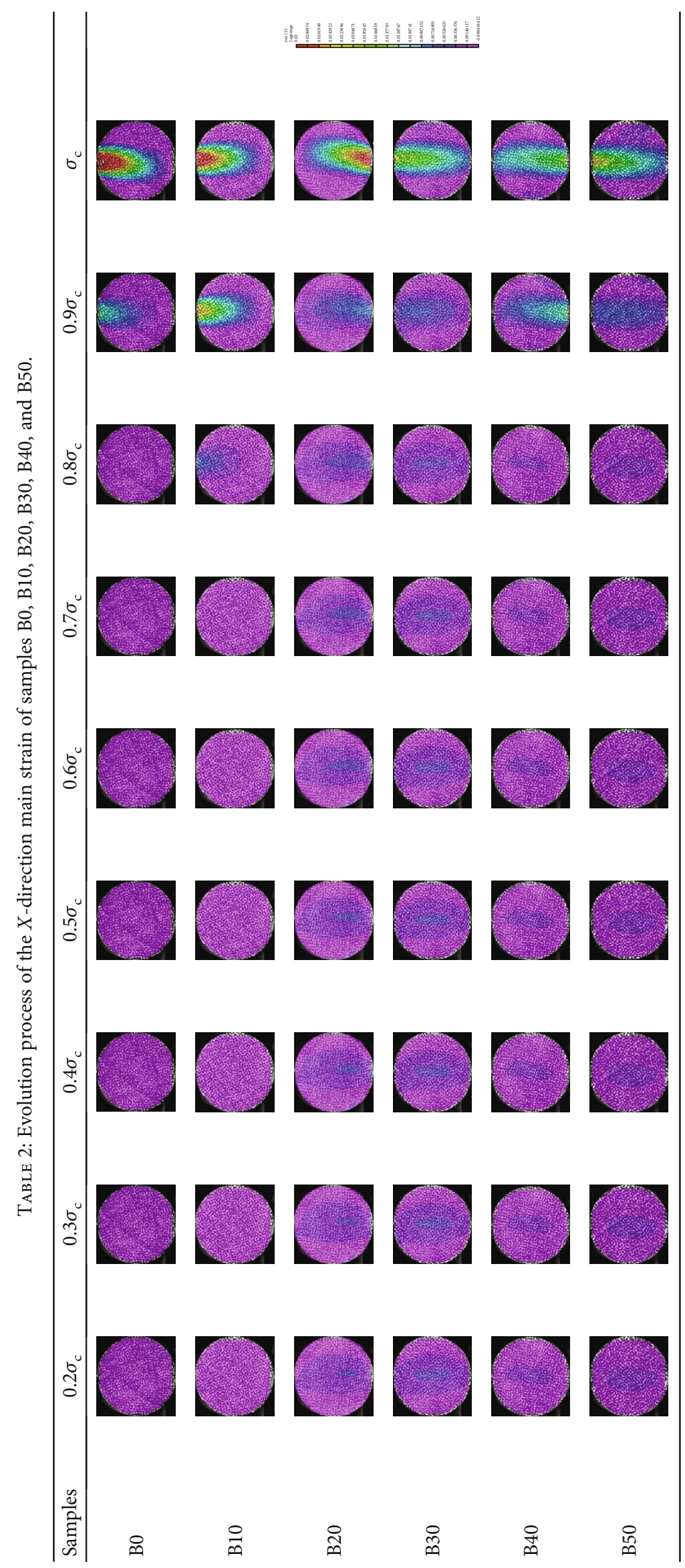




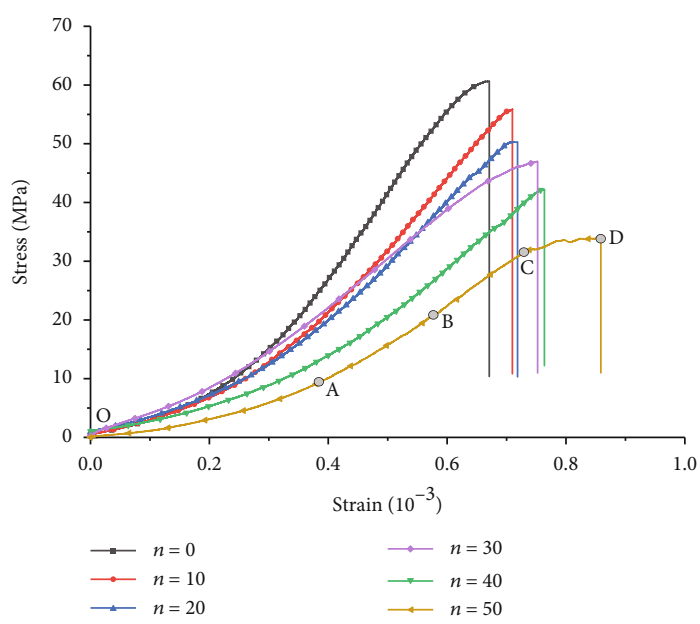

FIgURE 7: Stress-strain curves of uniaxial compression.

elastic modulus increases, and the damage variable decreases, resulting in a negative damage phenomenon. With the loading process, the sample is in the second stage (period of steady growth), the connection between mineral particles is destroyed, primary cracks expand, secondary cracks appear, cracks gradually converge, and the growth rate of the damage variable accelerates. Finally, the damage evolution enters the third stage (period of rapid growth), and a large number of cracks develop rapidly. When the load of the sample reaches the maximum, the main crack expands rapidly until the final barrier is broken through, and the sample is damaged. The damage variable increased sharply.

4.2.1. Damage Evolution Analysis of B50. In this part, the load-displacement curve and the damage-strain curve of sample B50 are compared and analyzed. As can be seen in Figure 9, taking B50 as an example, four key points $\mathrm{O}, \mathrm{A}, \mathrm{B}$, and $C$ were taken from the load-displacement curve of sample B50 for analysis. The damage-strain curve of sample B50 with 50 cycles of freeze-thaw treatment can be divided into three stages during the splitting test.

In the initial OA stage (linear elastic stage), the sample bears a small load. The damage variable was small, about 0.05. Due to the influence of freeze-thaw cycles, the internal damage of the sample accumulates seriously. Under the action of the load, the damage variable begins to increase. When it reaches the $\mathrm{AB}$ stage (elastic-plastic stage), new microcracks and micropores begin to appear inside the sample and continue to develop stably. The growth rate of the damage variable increased significantly and increased to 0.9 . When approaching the maximum load, the specimen is in the BC stage (failure stage). The strain develops intensively along the loading diameter, cracks appear on the loading diameter, and transient fracture occurs. The damage variable reached the maximum value [28-35].

4.3. Damage Analysis of Samples under the Uniaxial Compression Test. The damage evolution process of U0, U10, U20, U30, U40, and U50 specimens has been analyzed. After the image analysis software was used to obtain the prin- cipal strain of the strain field in the $X$-direction of the sample, and the maximum standard deviation of the principal strain in the $X$-direction was calculated, the maximum standard deviation was substituted into Equation (2) to calculate the damage variable.

As shown in Figure 10, the damage evolution process of sandstone samples treated by freeze-thaw cycles under uniaxial compression tests can be divided into three stages: in the first stage (period of slow or negative growth), the sandstone will undergo a compaction process at the initial stage of loading, during which the microcracks and micropores in the sandstone will be closed. (Of course, new microcracks and micropores may occur, but the closing trend is greater than the generating trend.) In this way, the rock's elastic modulus will increase, the damage variable of the rock will decrease, and the rock will produce negative damage. This process will approximately continue until the rock enters the linear elastic stage. After that, the damage evolution of rock enters the second stage (period of steady growth), in which the damage variable of rock begins to increase continuously, which means that the generation trend of microcracks and micropores in the rock is greater than the closing trend. This stage occurs until the macroscopic failure of rock. After a macroscopic failure occurs, the damage evolution of rock enters the third stage (period of rapid growth) of accelerated development, in which the damage development of rock is obviously accelerated. Finally, the rock loses its bearing capacity completely, and the damage variable is close to the ultimate damage variable of rock failure [36-46].

When the number of freeze-thaw cycles exceeds 10, the specimen is greatly affected by freeze-thaw cycles. Compared with the Brazilian splitting test, the damage variable of sandstone under uniaxial compression test changes slowly, which is consistent with the actual failure process of the sample and better verifies the feasibility and high precision of DIC used to measure the deformation and failure process of rock.

4.3.1. Damage Evolution Analysis of U50. In this part, the stress-strain curve and damage-strain curve of sample U50 are compared and analyzed. As can be seen in Figure 11, taking U50 as an example, five key points $\mathrm{O}, \mathrm{A}, \mathrm{B}, \mathrm{C}$, and D were taken from the stress-strain curve of sample U50 for analysis. The damage-strain curve of sample U50 with 50 cycles of freeze-thaw treatment during the uniaxial compression test can be roughly divided into four stages.

Due to the accumulation of damage in the sample under freeze-thaw cycles, the damage variable cannot be regarded as 0 before loading. Due to the action of load in the OA stage (crack closure stage), the internal microcracks and micropores of the sample are gradually compacted or even closed, resulting in negative damage to the rock. Then, the entire loading process enters the $\mathrm{AB}$ stage (linear elastic stage); that is, the linear elastic stage and the sandstone sample are further compressed. As far as the damage inside the specimen is concerned, it enters the linear elastic damage stage. In this stage, it is found that the apparent damage variable is small, and the damage degree of the specimen is low on the whole. When the loading stress level reaches the stress state of point $\mathrm{B}$, the damage of the sample begins to accumulate, and the 


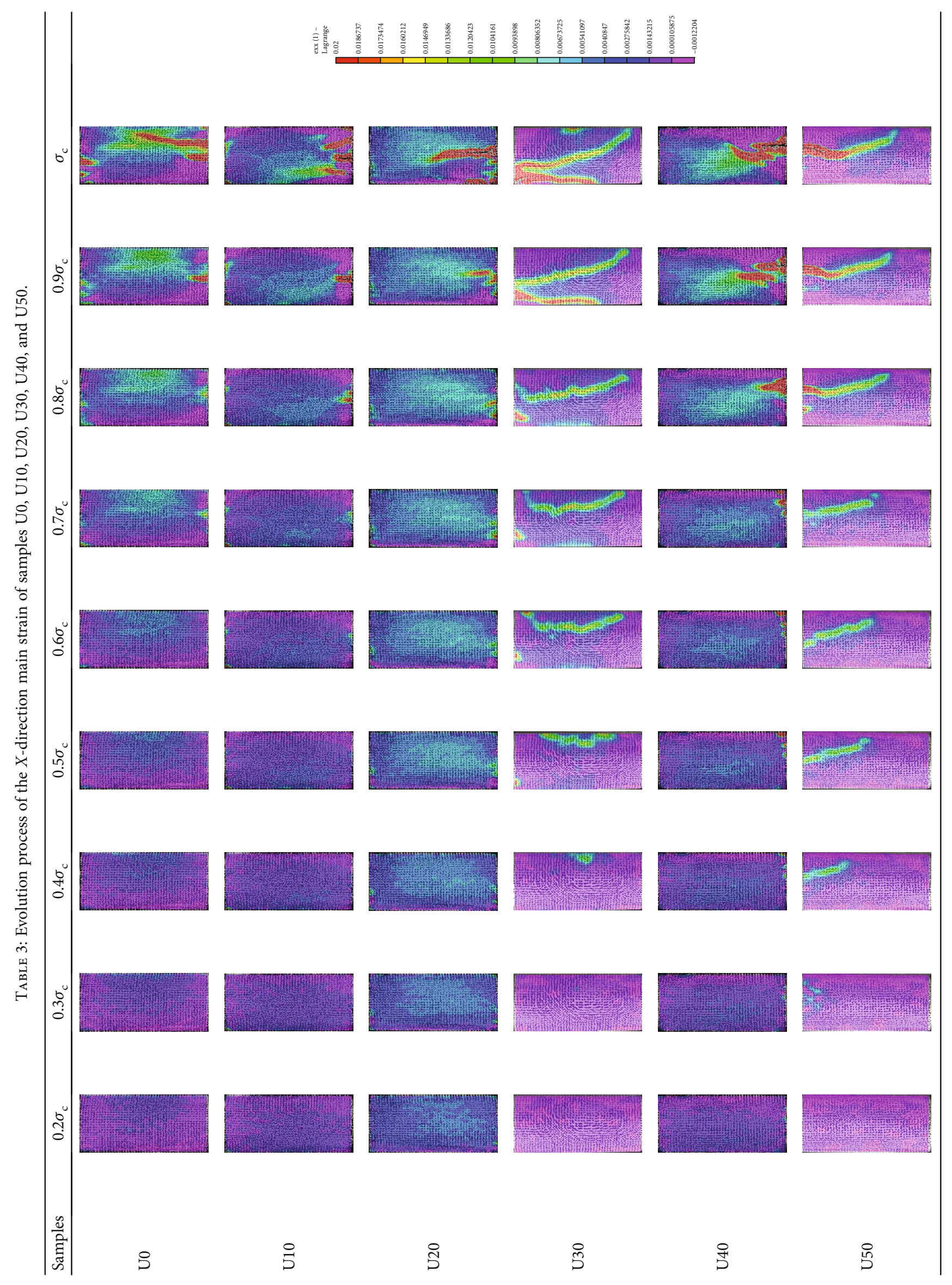




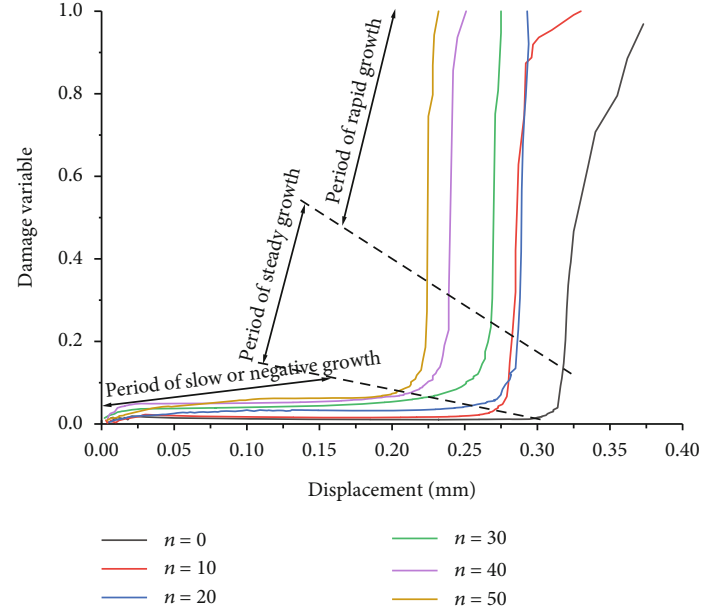

FIGURE 8: The damage variable evolution of B0, B10, B20, B30, B40, and B50 specimens.

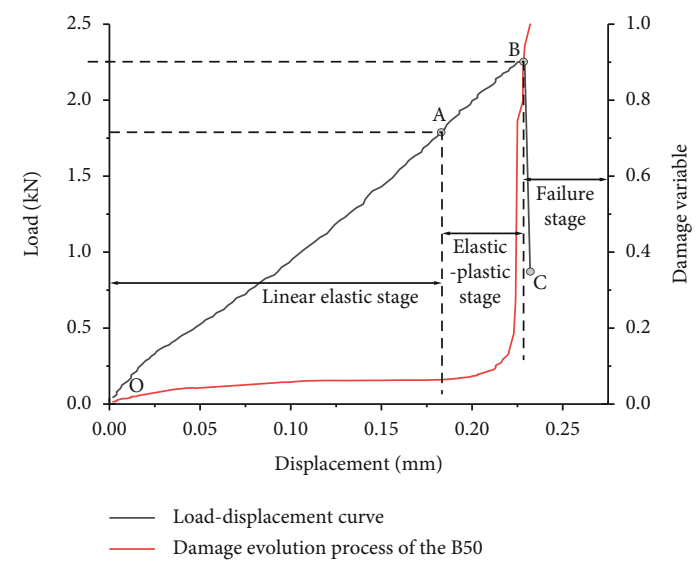

FIGURE 9: The relationship between the damage variable and the loading curve of the B50.

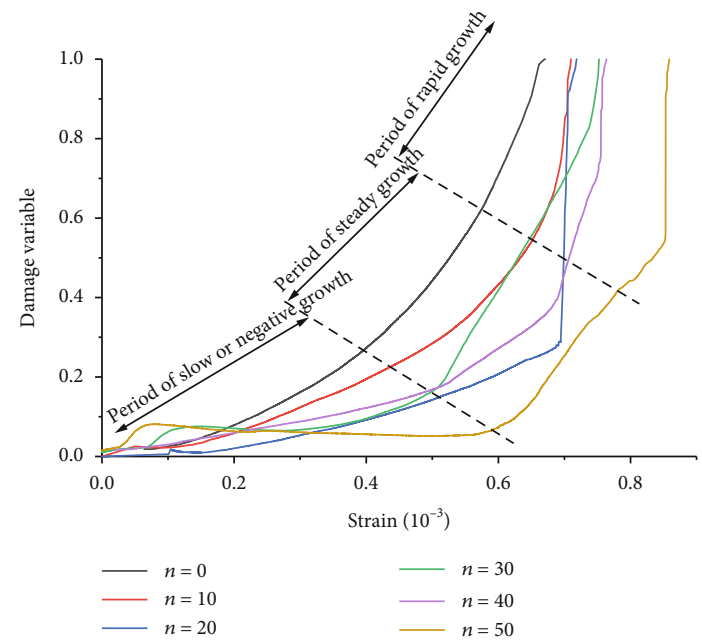

Figure 10: The damage variable evolution of U0, U10, U20, U30, U40, and U50 specimens.

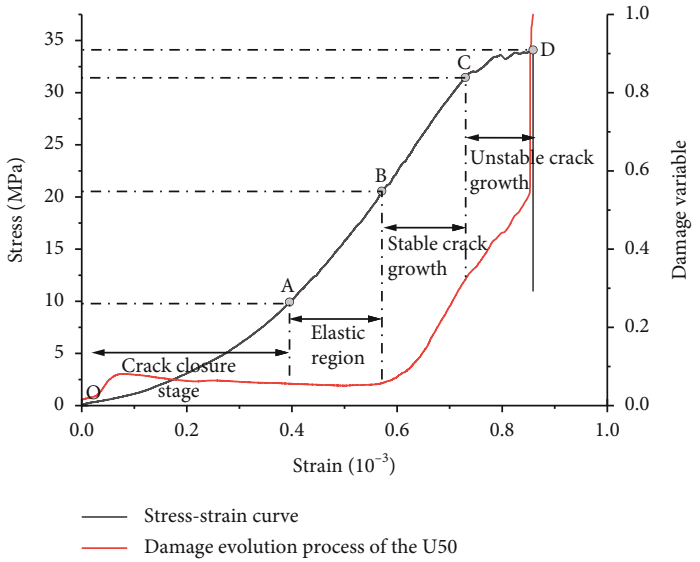

FIgURE 11: The relationship between the damage variable and the loading curve of the U50.

damage variable begins to evolve. The loading BC section (stable crack growth) of the sample is an elastoplastic development stage. Among them, the damage evolution develops from the inside of the specimen to the surface, and the damage variable value steadily increases, namely, the elastoplastic damage. The CD section (unstable crack growth) is the plastic stage, and the failure behavior of the specimen at this stage varies from microscopic failure to macroscopic failure. The damage variable increases sharply and reaches the plastic damage stage. When the whole loading process reached point $\mathrm{D}$, the value of the damage variable changed to 1 , and the bearing capacity of the specimen decreased rapidly.

\section{Conclusions}

The study of mechanical properties and the damage evolution process of rock mass in cold regions is an important issue for practical applications. In this paper, the DIC method is used to study the deformation characteristics and failure process of freeze-thaw-treated sandstone. Taking the standard deviation of principal strain as the damage variable, the damage evolution process of freeze-thaw-treated sandstone was quantitatively analyzed. Based on this study, the following conclusions can be drawn:

(1) During the whole process of freeze-thaw damage, the frost heave force generated by the constant change of water morphology makes the cracks expand and increase continuously, leading to the emergence of new cracks. The results show that the greater the number of freeze-thaw cycles, the lower the P-wave propagation velocity is

(2) According to the splitting test and uniaxial compression test of the sandstone samples after freeze-thaw treatment, the tensile strength and compressive strength of the sandstone samples after freeze-thaw treatment show a decreasing trend with the increase of the number of freeze-thaw cycles. Moreover, the more times the freeze-thaw cycles are treated, the faster the tensile strength and compressive strength decrease 
(3) Using DIC technology, it was found that with the increase of the number of freeze-thaw cycles, the internal pores and cracks in the Brazilian splitting disc became more and more intensive during the loading process, and the strain difference between the end and the middle of the sandstone gradually decreased. The crack initiation location of the Brazilian disc may change from the end to the middle. However, for the uniaxial compression test, due to the influence of the end effect, the localization strain band is always generated from one end and gradually widens and moves to the other end of the sample, finally forming an oblique or vertical localization strain band in the middle of the sample

(4) The full-field strain of the specimen surface was measured by the digital image correlation technique, and the damage variable which could characterize the deformation characteristics of the specimen was proposed based on the standard deviation of the principal strain. The damage evolution process of sandstone specimens after freeze-thaw treatment can be divided into three stages: the period of slow or negative growth stage, the period of steady growth stage, and the rapid growth stage. The results show that the proposed damage variables can better describe the damage evolution process of sandstone specimens after freeze-thaw treatment

\section{Data Availability}

Some or all data, models, or code that support the findings of this study are available from the corresponding author (demonjjun@126.com) upon reasonable request.

\section{Conflicts of Interest}

The authors declare that they have no conflicts of interest to this work. The authors also declare that they do not have any commercial or associative interest that represents a conflict of interest in connection with the work submitted.

\section{Acknowledgments}

This work was supported by the National Natural Science Foundation of China (52064006, 52004072, and 51779021), Science and Technology Support Project of Guizhou ([2020]4Y044, [2021]N404, and [2021]N511), Talents of Guizhou University (Grant No. 201901), and Special Research Funds of Guizhou University (Grant Nos. 201903, 202011, and 202012).

\section{References}

[1] X. Wang, L. Pan, H. C. Lau, M. Zhang, L. Li, and Q. Zhou, "Reservoir volume of gas hydrate stability zones in permafrost regions of China," Applied Energy, vol. 225, pp. 486-500, 2018.

[2] Y. Lai, W. Hui, W. Ziwang, L. Songyu, and D. Xuejun, "Analytical viscoelastic solution for frost force in cold-region tunnels,"
Journal of the China Railway Society, vol. 31, no. 3, pp. 227234, 2000.

[3] G. Xu, J. Qi, and H. Jin, "Model test study on influence of freezing and thawing on the crude oil pipeline in cold regions," Cold Regions Science and Technology, vol. 64, no. 3, pp. 262-270, 2010.

[4] M. Krautblatter, D. Funk, and F. K. Günzel, "Why permafrost rocks become unstable: a rock-ice-mechanical model in time and space," Earth Surface Processes \& Landforms, vol. 38, no. 8, pp. 876-887, 2013.

[5] S. P. Pudasaini and M. Krautblatter, "A two-phase mechanical model for rock-ice avalanches," Journal of Geophysical Research Earth Surface, vol. 119, no. 10, pp. 2272-2290, 2014.

[6] J. Bi, P. F. Liu, and F. Gan, "Effects of the cooling treatment on the dynamic behavior of ordinary concrete exposed to high temperatures," Construction and Building Materials, vol. 248, article 118688, 2020.

[7] P. C. Li and H. Wang, "A novel strategy for the crossarm length optimization of PSSCs based on multi-dimensional global optimization algorithms," Engineering Structures, vol. 238, article 112238, 2021.

[8] M. Fukuda, T. Harimaya, and K. Harada, "The study on effect of rock weathering by freezing and thawing to rock mass collapse," Gekkan-Chikyu, vol. 18, no. 9, pp. 574-578, 1996.

[9] L. Wen, X. B. Li, H. Y. Tang, and L. Weng, "Study of physicomechanical characteristics of rock under different frozenthawed circle temperature range and its engineering application," Engineering mechanics, vol. 34, pp. 247-256, 2017.

[10] A. Prick, "Critical degree of saturation as a threshold moisture level in frost weathering of limestones," Permafrost and Periglacial Processes, vol. 8, no. 1, pp. 91-99, 1997.

[11] X. Tan, W. Chen, J. Yang, and J. Cao, "Laboratory investigations on the mechanical properties degradation of granite under freeze-thaw cycles," Cold Regions Science \& Technology, vol. 68, no. 3, pp. 130-138, 2011.

[12] G. Khanlari and Y. Abdilor, "Influence of wet-dry, freeze-thaw, and heat-cool cycles on the physical and mechanical properties of upper red sandstones in Central Iran," Bulletin of Engineering Geology and the Environment, vol. 74, no. 4, pp. 12871300, 2015.

[13] L. Dexing, W. Enyuan, K. Xiangguo, J. Haishan, W. Dongming, and A. Muhammad, "Damage precursor of construction rocks under uniaxial cyclic loading tests analyzed by acoustic emission," Construction and Building Materials, vol. 206, pp. 169-178, 2019.

[14] Z. P. Zhang, R. Zhang, H. P. Xie, J. F. Liu, and P. Were, "Differences in the acoustic emission characteristics of rock salt compared with granite and marble during the damage evolution process," Environmental Earth Sciences, vol. 73, no. 11, pp. 6987-6999, 2015.

[15] C. A. Tang and X. H. Xu, "Evolution and propagation of material defects and Kaiser effect function," Journal of Seismological Research, vol. 13, no. 2, pp. 203-213, 1990.

[16] Z. Cui and W. Han, "In situ scanning electron microscope (SEM) observations of damage and crack growth of shale," Microscopy and Microanalysis, vol. 24, no. 2, pp. 107-115, 2018.

[17] X. Y. Wu, P. Baud, and T. F. Wong, "Micromechanics of compressive failure and spatial evolution of anisotropic damage in Darley Dale sandstone," International Journal of Rock Mechanics and Mining Sciences, vol. 37, no. 1-2, pp. 143-160, 2000. 
[18] X. Zhang, J. Chen, Z. Wang, N. Zhan, and R. Wang, "Digital image correlation using ring template and quadrilateral element for large rotation measurement," Optics and Lasers in Engineering, vol. 50, no. 7, pp. 922-928, 2012.

[19] B. Pan, K. M. Qian, H. M. Xie, and A. Asundi, “Two-dimensional digital image correlation for in-plane displacement and strain measurement: a review," Measurement Science \& Technology, vol. 20, no. 6, article 062001, 2009.

[20] L. B. Jiang, H. M. Xie, and B. Pan, "Speeding up digital image correlation computation using the integral image technique," Optics and Lasers in Engineering, vol. 65, pp. 117-122, 2015.

[21] Z. Y. Jiang, Q. Kemao, H. Miao, J. L. Yang, and L. Q. Tang, "Path-independent digital image correlation with high accuracy, speed and robustness," Optics and Lasers in Engineering, vol. 65, pp. 93-102, 2015.

[22] Y. L. Kang and H. M. Xie, "Micro and nano metrology in experimental mechanics," Optics and Lasers in Engineering, vol. 48, no. 11, pp. 1045-1045, 2010.

[23] P. Leplay, J. Rethore, S. Meille, and M. C. Baietto, "Identification of damage and cracking behaviours based on energy dissipation mode analysis in a quasi-brittle material using digital image correlation," International Journal of Fracture, vol. 171, no. 1, article 9624, pp. 35-50, 2011.

[24] H. Zhang, G. Y. Huang, H. P. Song, and Y. L. Kang, "Experimental investigation of deformation and failure mechanisms in rock under indentation by digital image correlation," Engineering Fracture Mechanics, vol. 96, pp. 667-675, 2012.

[25] S. P. Ma, D. Yan, X. Wang, and Y. Y. Cao, "Damage observation and analysis of a rock Brazilian disc using high-speed DIC method," Applied Mechanics \& Materials, vol. 70, pp. 87-92, 2011.

[26] M. M. Kou, X. R. Liu, Z. Q. Wang, and S. D. Tang, "Laboratory investigations on failure, energy and permeability evolution of fissured rock-like materials under seepage pressures," Engineering Fracture Mechanics, vol. 247, article 107694, 2021.

[27] Y. Y. Cao, S. P. Ma, X. Wang, and Z. Y. Hong, "A new definition of damage variable for rock material based on the spatial characteristics of deformation fields," Advanced Materials Research, vol. 146-147, pp. 865-868, 2010.

[28] Y. Zhao, C. L. Wang, and J. Bi, "Analysis of fractured rock permeability evolution under unloading conditions by the model of elastoplastic contact between rough surfaces," Rock Mechanics and Rock Engineering, vol. 53, no. 12, article 2224, pp. 5795-5808, 2020.

[29] Y. Zhao, C. L. Wang, Y. F. Zhang, and Q. Liu, "Experimental study of adsorption effects on shale permeability," Natural Resources Research, vol. 28, no. 4, article 9476, pp. 15751586, 2019.

[30] Y. Zhao, P. F. He, Y. F. Zhang, and L. Wang, “A new criterion for a toughness-dominated hydraulic fracture crossing a natural frictional interface," Rock Mechanics and Rock Engineering, vol. 52, no. 8, pp. 2617-2629, 2019.

[31] Z. J. Wu, L. F. Fan, Q. S. Liu, and G. W. Ma, "Micro-mechanical modeling of the macro-mechanical response and fracture behavior of rock using the numerical manifold method," Engineering Geology, vol. 225, pp. 49-60, 2017.

[32] Q. S. Liu, Z. C. Qian, and Z. J. Wu, "Micro/macro physical and mechanical variation of red sandstone subjected to cyclic heating and cooling: an experimental study," Bulletin of Engineering Geology and the Environment, vol. 78, no. 3, pp. 1485-1499, 2019.
[33] Z. J. Wu, X. Y. Xu, Q. S. Liu, and Y. T. Yang, "A zero-thickness cohesive element-based numerical manifold method for rock mechanical behavior with micro-Voronoi grains," Engineering Analysis with Boundary Elements, vol. 96, pp. 94-108, 2018.

[34] L. F. Fan, J. W. Gao, X. du, and Z. J. Wu, "Spatial gradient distributions of thermal shock-induced damage to granite," Journal of Rock Mechanics and Geotechnical Engineering, vol. 12, no. 5, pp. 917-926, 2020.

[35] F. Wu, H. Zhang, Q. L. Zou, C. B. Li, J. Chen, and R. B. Gao, "Viscoelastic-plastic damage creep model for salt rock based on fractional derivative theory," Mechanics of Materials, vol. 150, article 103600, 2020.

[36] W. Fei, L. Jie, Z. Quanle, L. Cunbao, C. Jie, and G. Renbo, “A triaxial creep model for salt rocks based on variable-order fractional derivative," Mechanics of Time-Dependent Materials, vol. 25, no. 1, pp. 101-118, 2021.

[37] X. P. Zhou, J. Bi, and Q. H. Qian, "Numerical simulation of crack growth and coalescence in rock-like materials containing multiple pre-existing flaws," Rock Mechanics and Rock Engineering, vol. 48, no. 3, pp. 1097-1114, 2015.

[38] J. Bi, X. P. Zhou, and Q. H. Qian, “The 3D numerical simulation for the propagation process of multiple pre-existing flaws in rock-like materials subjected to biaxial compressive loads," Rock Mechanics and Rock Engineering, vol. 49, no. 5, pp. 1611-1627, 2016.

[39] J. Z. Zhang and X. P. Zhou, "AE event rate characteristics of flawed granite: from damage stress to ultimate failure," Geophysical Journal International, vol. 222, no. 2, pp. 795-814, 2020.

[40] X. P. Zhou, Y. X. Zhang, Q. L. Ha, and K. S. Zhu, "Micromechanical modelling of the complete stress-strain relationship for crack weakened rock subjected to compressive loading," Rock Mechanics and Rock Engineering, vol. 41, no. 5, pp. 747-769, 2008.

[41] Y. Zhao, J. Bi, C. L. Wang, and P. F. Liu, "Effect of unloading rate on the mechanical behavior and fracture characteristics of sandstones under complex triaxial stress conditions," Rock Mechanics and Rock Engineering, no. article 2515, 2021.

[42] Y. T. Yang, X. H. Tang, H. Zheng, Q. S. Liu, and L. He, “Threedimensional fracture propagation with numerical manifold method," Engineering Analysis with Boundary Elements, vol. 72, pp. 65-77, 2016.

[43] Y. T. Yang, X. H. Tang, H. Zheng, Q. S. Liu, and Z. J. Liu, "Hydraulic fracturing modeling using the enriched numerical manifold method," Applied Mathematical Modeling, vol. 53, pp. 462-486, 2018.

[44] Y. Zhao, C. L. Wang, M. Y. Teng, and J. Bi, "Observation on microstructure and shear behavior of mortar due to thermal shock," Cement \& Concrete Composites, vol. 121, article 104106, 2021.

[45] Y. Zheng, C. X. Chen, T. T. Liu, and Z. H. Ren, “A new method of assessing the stability of anti-dip bedding rock slopes subjected to earthquake," Bulletin of Engineering Geology and the Environment, vol. 80, no. 5, article 2188, pp. 3693-3710, 2021.

[46] S. Q. Yang and H. W. Jing, "Strength failure and crack coalescence behavior of brittle sandstone samples containing a single fissure under uniaxial compression," International Journal of Fracture, vol. 168, no. 2, pp. 227-250, 2011. 